\author{
УДК 340.13 \\ DOI 10.18413/2712-746X-2020-45-4-732-741
}

\title{
Национальная идея в конституции России: теоретическая оценка ключевых положений
}

\author{
Куксин И.Н., Селихов Н.В., \\ Белгородский государственный национальный исследовательский университет, \\ Россия, 308015, г. Белгород, ул. Победы, 85 \\ E-mail: proffKuk-1944@yandex.ru; selihovnv@mail.ru
}

\begin{abstract}
Аннотация. Национальная идея - основной принцип устройства жизни нации, который она формирует, осуществляет и развивает. Следовательно, национальная идея - это нечто такое, что объединяет, консолидирует общество, способствует превращению населения в народ. Она так или иначе всегда будет связана с духовными ценностями, господствующими в обществе. Но как это реализовать на практике, чтобы она была достоянием народа, была основой его объединения, консолидации? Авторы предлагают пути формулирования и наполняемость национальной идеи в России через конституцию. Национальная идея, сформулированная в конституционных постулатах, выступает не абстрактным явлением, а базой политико-правового единства народа. Авторы связывают объективные трудности выработки такой идеи с самой конституцией, её идейно-идеологическим несовершенством. Авторы приходят к выводу о необходимости дальнейшей конституционной реформы.
\end{abstract}

Ключевые слова: патриотизм, конституция, классовое государство, идеология, права человека, народный суверенитет, представительная демократия.

Для цитирования: Куксин И.Н., Селихов Н.В. 2020. Национальная идея в конституции России: теоретическая оценка ключевых положений. NOMOTHETIKA: Философия. Социология. Право. 45 (4): 732-741. DOI 10.18413/2712-746X-2020-45-4-732-741

\section{National idea in the Russian constitution: theoretical assessment of key provisions}

\author{
Ivan N. Kuksin, Nikolay V. Selikhov \\ Belgorod National Research University, \\ 85 Pobeda St, Belgorod, 308015, Russia \\ E-mail: proffKuk-1944@yandex.ru; selihovnv@mail.ru
}

\begin{abstract}
Annotation. The national idea is the basic principle of the nation's life structure, which it forms, implements and develops. Therefore, the national idea is something that unites, consolidates society, and contributes to the transformation of the population into a people. In one way or another, it will always be linked to the spiritual values that prevail in society. But how can this be implemented in practice, so that it is the property of the people, the basis for their unification and consolidation? The authors suggest ways to formulate and fill the national idea in Russia through the Constitution. The national idea formulated in the constitutional postulates is not an abstract phenomenon, but the basis of the political and legal unity of the people. At the same time, the authors associate the objective difficulties of developing such an idea with the Constitution itself, its ideological and ideological imperfection. The authors come to the conclusion about the necessity of further constitutional reform.
\end{abstract}

Key words: patriotism, Constitution, class state, ideology, human rights, popular sovereignty, representative democracy. 
For citation: Kuksin I.N., Selikhov N.V. 2020. National idea in the Russian constitution: theoretical assessment of key provisions. NOMOTHETIKA: Philosophy. Sociology. Law series. 45 (4): 732-741 (in Russian). DOI 10.18413/2712-746X-2020-45-4-732-741

\section{Введение}

Над проблемой национальной идеи бьются лучшие умы России ни одно десятилетие, что свидетельствует о том, что она имеет длительную историю. Ей посвящены многие научные исследования, среди которых следует особо выделить шеститомный коллективный труд под названием «Национальная идея России» ${ }^{1}$, в создании которого принимали участие доктор политических наук Владимир Якунин, победитель конкурса молодых российских ученых - докторов наук Вардан Багдасарян, главный научный сотрудник Института социально-политических исследований РАН, профессор кафедры государственной политики факультета политологии МГУ Сергей Кара-Мурза.

При все сложности текущего момента к этой проблеме приковано внимание и руководства страны. Так, президент России В.В. Путин неоднократно в разные годы обращался к этой идее и высказывал свое ее понимание. Так, тема поисков национальной идеи получила своё развитие в первом Послании президента Федеральному собранию РФ 8 июля 2000 г.: «Единство России скрепляют присущий нашему народу патриотизм, культурные традиции, общая историческая память» ${ }^{2}$. В третьем Послании Федеральному собранию РФ 18 апреля 2002 г. президент обозначил, что именно считает самым важным и первоочередным для России и россиян: «Мы должны сделать Россию процветающей и зажиточной страной. Чтобы жить в ней было комфортно и безопасно. Чтобы люди могли свободно трудиться, без ограничений и страха зарабатывать для себя и для своих детей. И чтобы они стремились ехать в Россию, а не из неё. Воспитывать здесь своих детей, строить здесь свой дом» ${ }^{3}$.

В мае 2020 года в интервью для телевизионной программы «Москва. Кремль. Путин» президент подчеркнул, что «национальная идея России заключается в патриотизме, выраженном в служении развитию страны... и других вариантов национальной идеи быть не может. Патриотизм должен быть не квасным,... а направленным на развитие страны» ${ }^{4}$

Это не первая попытка лидера страны сформулировать национальную идею для современной России. Дмитрий Медведев, выступая 22 января 2008 года на II Общероссийском гражданском форуме, оговорившись вначале, что «дискуссию на эту тему я считаю малоэффективной», тем не менее продолжил: «Но уверен, что у каждой нации должен быть набор понятных принципов и целей, которые объединяют людей, живущих в одной стране. И строятся эти принципы на вполне реальных задачах, востребованных обществом. Каковы эти принципы? Как они видятся сегодня? Это, прежде всего, свобода и справедливость. Второе - это гражданское достоинство человека. Третье - его благополучие и социальная ответственность» ${ }^{5}$. Конечно, последний термин употреблен в самом широком смысле [Makogon, Savel'eva, Lyahkova, Parshina, Emel'anov, 2017].

Таким образом, можно утверждать, что поиск формулировки национальной идеи и ее наполняемости продолжается. И подтверждением этого служит тот факт, что нынешний и бывший президенты России сочли нужным в своих речах и посланиях касаться духовных ценностей и национальной идеи, говорить о ее востребованности в народе. Не-

${ }^{1}$ Национальная идея России: «Моя страна должна быть, должна быть всегда!». М.: Научный эксперт. С. 4440

${ }^{2}$ http://www.kremlin.ru/acts/bank/22401

${ }^{3} \mathrm{http}: / / \mathrm{www} \cdot k r e m l i n . r u /$ acts/bank/36351

${ }^{4} \mathrm{https}: / / \mathrm{rg} . \mathrm{ru} / 2020 / 05 / 11 /$ vladimir-putin-rasskazal-o-svoem-ponimanii-nacionalnoj-ideirossii.html

${ }^{5}$ https://forum-msk.org/material/society/482385.html 
ослабевающую актуальность этой проблемы в 2007 году предвидел В.В. Путин: в восьмом Послании Федеральному собранию РФ (26 апреля 2007 г.) в его заключительной части мы находим следующее: «А у нас с вами, в России, есть ещё такая старинная русская забава поиск национальной идеи. Это что-то вроде поиска смысла жизни. Занятие в целом небесполезное и небезынтересное. Этим можно заниматься всегда и - бесконечно»1

Приведенные выше мнения, доводы и предложения придают этой проблеме разнонаправленный характер. Наверное, не только патриотизм, но и православие, соборность, универсализм, либеральный прогрессивизм, представительный демократизм и прочие концепты выступают основой социального единства россиян. Следует признать, что каждый из них достоин внимания и своего места в российской государственности, так как выступают непреходящими ценностными ориентирами. Но ни один из них всецело не формирует нашего универсума, не предопределяет действительности, и тем более не приоткрывает нашего будущего.

\section{Национальная идея - основание политико-правового единства народа}

Проблема раскрытия смысла национальной идеи, ее внутренней наполняемости, это удел не только науки. Она остаётся желанной, востребованной, но поныне не огранённой сущностью. Лучшие умы корпят над её формулировками, предлагают пространные труды, всевозможные конструкции и модели. Однако окончательного результата на сегодняшний день так и нет. «Почему?» - возникает вопрос. По мнению авторов, усилия по поиску национальной идеи России характеризуются объективными трудностями, и самая главная трудность - это выбор ее основы, а уже затем - формулирование и закрепление.

Современный исторический период, который переживает Россия, дает возможность выхода из сложившегося тупика. По крайней мере, юриспруденция использует собственную точку опоры, полагаясь на конституционную теорию. Именно конституция, как верно заметил А.Н. Кокотов, - «это политико-правовая и духовно-идеологическая основа жизнедеятельности общества "на вырост". Многие её положения выступают целями, которые еще предстоит достичь, а не констатацией того, что есть» ${ }^{2}$.

Получается, что национальная идея - основание политико-правового единства народа. Юридическим вместилищем национальной идеи любого государства является конституция. Содержание и форма - так соотносятся между собой национальная идея и конституция.

Конституция России чётко расставила приоритеты развития государственного строя: народный суверенитет, верховенство прав и свобод человека, правовое и социальное государство. Большинство иных положений раскрывают упомянутые постулаты.

Хребет российского государства выглядит прочным, его очертания вполне конкретны. Трудно избежать очарования заявленных идей, справиться с искушением стать верным адептом конституционных сущностей и принципов [Kuksin, Markhgeym, Novikova, Tonkov, 2016], заняться позитивными прогнозами политического будущего нашего общества. Но если вдуматься глубже, то будущее российского народа таково: возглавляемый политическим представительством, он уверенно движется в сторону социально разобщенного общества, признающего неравенство своих граждан. Поводы к данной теоретической оценке следующие.

1. Признанная научным миром диалектика социального развития предполагает прогрессивное движение общества от одной идеи социального единства к другой через снятие общественных противоречий посредством борьбы и единения. Последние образуют диалектическую пару, вскрывающую причины перемены государственного строя народов.

\footnotetext{
${ }^{1}$ http://www.kremlin.ru/acts/bank/25522/page/4

${ }^{2}$ Кокотов А.Н. Личная переписка от 16.07.2017 года (архив автора)
} 
Начнём с того, что идея народного суверенитета, сформулированная западной мыслью в эпоху становления индустриального общества, изначально детерминирована опекой масс политическим представительством. Конструкт усечённого народовластия (представительной демократии) иерархичен и свойственен классовому государству с понятной общественной структурой. Социально-экономический статус, обусловленный владением средствами производства, эксплуатацией наёмного труда и особым распределением национального продукта, перемежевал сословное политическое сообщество в классы буржуазии, рабочих и крестьян. Каждый из них занял собственную социальную нишу, получил определённые политические и экономические права и возможности. Взаимодействие между ними выстроено через выборное представительство, бытующее на партийной основе. Политические представители классового общества взаимодействуют в парламенте, ставшем официальной площадкой обсуждения межклассовых интересов. Идея непосредственного участия народа в управлении государственными делами не обсуждается. Все важнейшие государственные полномочия и функции конституционно закреплены за представительными органами. В том сущность классового государства, его скрепы - избирательное право и выборные органы власти. Концепт представительной демократии стал витриной современного государства.

В развитых странах эпоха становления индустриального общества завершилась с началом XX в. Классовое государство устояло повсеместно. От государства сословного остались лишь потускневшие фамильные гербы, ржавые доспехи, громкие титулы, бесправные сословные собрания и праздные монархические династии, лишённые реального управления.

Такова социальная диалектика. Старое отмирает, новое рождается и развивается.

2. Весь XX в. классовое государство двигалось путями политической борьбы за государственный аппарат и строительство нового общества. Борьба и единение велись в представительном формате. Многопартийная западноевропейская система соперничала с монопартийным социализмом, плюралистическое общество противопоставлялось монолиту советского народа. Парламент выставлялся альтернативой Верховного Совета, свободный мандат окорачивался императивностью полномочий. Эти идеи провозглашались конституционно. Они породили двухполярный человеческий универсум с ясными эмпирическими формами социалистической и капиталистической систем.

Однако эйфория представительного согласия классового государства длилась недолго. Со временем социальное неравенство отравило жизнь политического сообщества нарастающими противоречиями. Разница социального положения граждан сказывалась на их возможностях, вызывала всеобщую напряженность. Кристалл социально-классовой структуры такого государства изобиловал точками напряжения, которые политическое представительство так и не смогло ослабить. Общественное разобщение и неравенство только усилились.

В XX в. проблему социального неравенства решали по-разному.

Социалистическая система заявила о ликвидации данного явления через изменение социальной структуры силой идеологии и закона. Классы-антагонисты изводились под корень юридически, провозглашался нерушимый союз рабочих, крестьянства и трудовой интеллигенции. В образе советского народа эта дружественная спайка олицетворялась с обществом всеобщего равенства.

Западноевропейское классовое государство предложило собственную формулу сглаживания социальных диспаритетов. Более справедливое перераспределение национального продукта между формально равными гражданами считалось адекватным задаче средством. Цель всеобщего равенства возможностей не провозглашалась. Искомым идеалом виделась достойная жизнь.

Соревнование идей всеобщего равенства (социалистического государства) и достойной жизни (социального государства) длилось десятилетиями. Правда, ни одна из них 
в полном объёме своих целей не достигла. Советскому народу не удалось справиться с остатками номенклатурных привилегий, социальное государство так и не уравняло индивидуальных возможностей. Исправить ситуацию не помогли даже заимствования отдельных идей оппонентов. Практика показала, что классовый взгляд на общество априори не может побороть идею неравенства, сломать её основу - социальную иерархию. По этой причине социально-классовая структура не предполагает полного равенства прав и возможностей граждан в принципе, нуждается в социальной гегемонии. Без неё классовое государство лишается вертикальной оси, теряет смысл внутренней организации. Его жизнь поддерживает система партийно-политических социальных лифтов советского или западно-либерального типов, отражающих и культивирующих общественную градацию. В этой связи идеи всеобщего равенства и достойной жизни в классовом государстве нереализуемы в принципе, они антиподы по натуре.

3. С опытом проявилось несовершенство концептов социалистического и социального государств. Это привело к осознанию проблемы поиска дальнейших путей развития государственности, к качественному переосмыслению современной природы социального неравенства, обновлению идей демократии и представлений о народном суверенитете. Такова диалектическая логика.

Но в постсоветской России этого не случилось. Не то, чтобы диалектика утратила объективность, скорее отсутствие идей заставило в 1993 году авторов Конституции России принять сторону социально-правового государства. Этот шаг можно назвать попыткой унификации политических систем на базе классово разобщенного общества. Для России эта попытка имела явно регрессивные последствия.

Особенность момента продиктована следующими обстоятельствами:

- в России отсутствовали классы-антагонисты, да и сама структура общества уже не признавалась классовой (мешала целостная натура советского народа);

- отсутствовали политико-экономические основания для классового размежевания советского народа (частная собственность и устоявшаяся многопартийная система);

- государственная власть не рассматривалась объектом политической борьбы идеологически разобщённых групп;

- общественное сознание российского народа не ориентировалось на какую-то конкретную классовую идеологию.

В этих условиях основания социального единства российского народа прописывались исключительно искусственно с оглядкой на опыт бывших идеологических противников. Случилась упомянутая А.Н. Кокотовым «болезнь самоотречения» [Кокотов, 2018, c. 11] с её безудержным заимствованием, пренебрежением к национальной самобытности и сложившемуся общественному правосознанию. В результате европейничанья [Данилевский, 2018, с. 167] конституционно утвержден незнакомый советско-российскому народу государственный строй, добавивший свои «болячки» к прежним нездоровым симптомам. Номенклатура не исчезла, переродилась в правящую бюрократию. Вход на высший этаж теперь исключительно по партийной лестнице. Системообразующие партии - основные парламентские распределители национального продукта с бюджетным финансированием. Политическое представительство сохранило роль опекуна российского народа. То, что раньше клеймилось советской юриспруденцией, [Гуревич, 2018, с. 167] ныне названо прогрессивным достижением.

Крайнее имущественное расслоение, спорная приватизация общенародного имущества, налоговое засилье, партийные и парламентские кризисы, угасание самоуправления на местах и прочие последствия наложения европейских клише на российскую действительность. Об этом не писал только ленивый. Теперь это норма нашего бытия. Живём от кризиса к кризису с их трансформациями [Тонков, 2011], от выборов к выборам, от одной правящей партии к другой. Россия перманентно впадает в состояние переходного гос- 
ударства [Сорокин, 2010, с. 20-37]. В прочем, в сходном положении оказались все современные развитые государства.

4. Народный суверенитет в отечественной юриспруденции теперь плотно ассоциируется с представительной демократией, с правлением выборной бюрократии.

Статья 3 Конституции России допускает осуществление власти народом непосредственно и через представительные органы. Референдум и выборы - прямое выражение власти народа. Считается, что прямая и представительная демократия взаимно дополняют друг друга. Всё это напоминает нормативное примирение противоречивых сущностей.

Одна тонкость: конституционный текст изобилует подробностями о формировании представительной и исполнительной власти, её полномочиях, но почти безмолвствует о непосредственной демократии. Идея делегации власти народа к представительным органам прописана чётко. Суверенитет народа остался юридической фикцией.

Нечто похожее случилось и с другими «краеугольными камнями» российской конституции. Социальное и правовое государство оказалось «резиновой» сущностью, субъективно наполняемой теорией. Ни один зарубежный или отечественный труд не раскрыл объективных признаков названных ноуменов, не усомнился в их непорочности. На фоне всеобщего одобрения постулатов современной государственности позиция И.С. Романчука явно выбивается из хвалебного ряда. Слепое подчинение всепоглощающему закону [Романчук, 2010, с. 66-69], установленному политическим представительством, - сомнительная аксиома без надлежащих доказательств. Трудно воспринять её основой социального единства. Так же как невозможно согласиться и с тем, что смысл государства в более справедливом перераспределении благ в условиях социального неравенства.

Ни совершенствование перераспределительных механизмов, ни неукоснительное следование в юридическом процессе [Макогон, 2017] позитивному праву не устраняют главного порока классового государства - проблемы социального неравенства. Оно остаётся системообразующим фактором. И в этом смысле заимствование конструктов социального и правового государства в Конституцию России не принесло нам ощутимой пользы. Они дополнили друг друга как невнятное содержание и неясная форма, не привнесли свежей идеи в государственное строительство, не укрепили политического единства российского народа.

На этом фоне выстроенная и рекламируемая система социальной поддержки граждан не выглядит принципиально новым достижением. Выплаты, льготы, социальные, образовательные, инфраструктурные и прочие расходы предусматривались и социалистической системой. Были они в разы больше нынешних, также имели нормативное отражение. Советское государство можно смело называть социальным и правовым. Широкое участие масс в управлении публичными делами и социалистическая законность, опиравшаяся на общественное сознание, имели под собой чёткую идеологическую догму и реальную поддержку населения.

В современной России действует несколько иной механизм. Скупою рукой народные избранники окормляют обедневших граждан из общего бюджета. Достойная жизнь многих сведена к физическому выживанию. В условиях отсутствия официальной идеологии такая реальность поочерёдно ввергает массовое сознание то в правовой инфантилизм, то в правовой нигилизм. Ориентиры государственного развития меняются от одного послания президента к другому, представительные органы превратились в нормотворческие фабрики, выпускающие сборники запретов и детальных регламентаций. Неужели в этом заключена «изюминка» постсоветского социального и правового «созидающего» [Борисов, Комаров, Кучин, Мархгейм, Нифанов, Новикова, Носков, Тонков, 2016] государства?

Нечто похожее случилось и с идеей прав человека. Статус советского человека активного строителя собственного государства - сменился казуальным набором прав и свобод испуганного гражданина, спасающегося от государственного насилия. Политическая сплоченность общей идеей участия в построении государственности заместилась 
идеей сохранения пространства, свободного от государственного вмешательства [Кокошкинъ, 1898, с. 233]. Политический индивидуализм выставлен наследником политического коллективизма, а юридический субъективизм (частный интерес) взбунтовался против правового объективизма (всеобщего интереса).

Прав был Ф.Ф. Кокошкин, утверждавший об ошибочности разложения права свободы человека на отдельные субъективные правомочия. Это заблуждение - путь к юридическому абсурду (неограниченному списку субъективных прав) [Кокошкинъ, 1898, с. 236], противопоставления общего и частного, части и целого (человека и общества). Россия твердо встала на этот путь.

Следственно, ключевые сущности российской конституции являются атрибутами классового государства. Общий смысл таковых в стратификации общества, основанной на неравенстве граждан.

Возможно ли возрождение в современной России классового государства с иерархически раскроенным политическим сообществом? Такая цель недостижима, она прямо противоречит политическому сознанию российского народа. И вот почему.

Во-первых, социально-классовая структура позитивному праву безразлична, нормативная база, признающая классовое строение, отсутствует. На уровне закона превозносятся принципы формального равенства прав всех индивидов без оглядки на их политический или экономический статус.

Во-вторых, политическая идеология как основной источник представлений о социальной дифференциации давно лишилась корпоративной (сословной, классовой) оболочки. Теперь всякая идеология стремится овладеть всем общественным сознанием.

В-третьих, на уровне сознания (общественного, коллективного, индивидуального) не осталось практических или теоретических предпосылок реинкарнации классовой общества.

Обыденное сознание далеко от классовых различий. Никто из рядовых граждан официально не причисляет себя к пролетариату, крестьянству или прогрессивной интеллигенции. Прежняя классовая линейка неактуальна, новой шкалы так и не возникло. В обиходе нет какого-либо классового деления, формальное социальное неравенство на практике измеряется социальным статусом, т.е. объёмом политических и экономических возможностей.

Попытки научного сообщества вновь нащупать под ногами «классовую» почву обречены на провал. Причина объективна. Теоретическое сознание находится вне исключительной орбиты научной эмпирии, не способной выявить новые истинные закономерности и основополагающие факторы классового разграничения, предложить адекватные стандарты и приёмы теоретизирования, свойственные каждой эпохе [Мамут, 1989, с. 23]. В этой связи современные классовые ряды нередко обретают причудливый вид: средний класс, класс предпринимателей и менеджеров [Ревина, 2000, с. 45-50]; богатые и бедные; слои молодых, неженатых, высшей и массовой интеллигенции [Заславская, 1995, с. 9-11]; высший, средний, нижний (социальное дно) классы [Ермаков, 2013, с. 106-110]; элита, солариат, пролетариат и прекариат [Тощенко, 2018, с. 76-77] и т.п. Перечислить и системно воспринять все классификации невозможно. Бесчисленные эмпирические критерии не «цепляют» научное сознание. Не помогают даже западные дуральные, плюральные и смешанные приёмы [Классовые схемы ... 2017, с. 7-23]. Наоборот, ощущается какая-то крайняя субъективная производность, растерянная «притянутость». Социологи пытаются оправдать жизнеспособность классового подхода с помощью опытных категорий («респонденты», «кластеры», «индексы», «модусы», «многофакторный подход», «неэкономический капитал» и т.п.), но не могут ухватить настоящую природу социальной стратификации, живут эмпирическими догадками, лишенными философско-идеологической основы. Трудно вывести объективную классовую природу современного общества на основе эмпирических переменных (занятости, профессии, трудового опыта, достатка, уровня расходов и т.д.). 
Между тем диалектическая и формальная логика оперируют ясными сущностями. Эмпирическая туманность лишает их онтологической ценности, возможности точного прогнозирования. Нет ясного современного понимания социального класса, значит, сама идея классового разграничения общества утратила жизнеспособность. Тот, кто не согласен с данным выводом, должен представить обратное научное обоснование, равное по высоте мыслям К. Маркса. До того момента тяга к классовой дифференциации кажется фантомом прежнего мировоззрения.

Однако следует согласиться, что политическое сообщество никогда не будет однородным. Оно последовательно пережило сословную, а затем и классовую стратификацию. Теперь ищет иную основу размежевания индивидов. Пока неясна его суть, но сегодня вполне просматривается горизонтальная архитектоника политических связей людей. На индивидуальном уровне равенство прав корреспондирует равенству возможностей. Социальная иерархия утрачивает формообразующее значение в политическом единстве. Потребности в коллективном самоопределении граждан, некогда разделявшем общество на сословия и классы, уже не ощущается. Общественное сознание не проявляет тяги к устойчивым массовым формам коммуникации, к социальному гегемону, единолично определяющему вектор общественного развития. В приоритете индивидуализм. На этом основании равенство интересов всех субъектов политического общения презюмируется, в т.ч. нормативно.

В этой связи предполагается, что социальная структура политического сообщества, образующего государство, изменится коренным образом. Линией разграничения граждан станет аксиологическое сознание [Мамут, с. 11], отражающее воспринятые на общественном, коллективном и индивидуальном уровне политические ценности, ориентации и приоритеты. Социальная разнородность проявится в принадлежности индивида к определенной аксиологической системе (идеологии), стремящейся к всеобщности. Борьба таких систем за общественное сознание предопределит направление развития всякого государства, обеспечит единство лиц, вступающих в политические связи. Эмпирически это единство образует политическое сообщество свободных и равных индивидов. В нём политическая свобода проявляется в выборе идеологии, а равенство в участии управлении общественными делами.

\section{Заключение}

Изложенное позволяет сформулировать некоторые выводы и высказать предложения.

1. Применительно к поиску российской национальной идеи трудно представить, что сознание нашего народа повернулось к уже апробированной идее классового государства во всех его проявлениях (правового и социального государства), признало безупречными его ценности (усечённый народный суверенитет и верховенство прав человека), потянулось к неизбежной социальной иерархии и неравенству. Эти лозунги более не привлекают людей, воспринимаются движением назад, воссозданием политических моделей, пережитых другими народами. Следовательно, отказ нашего общества от идей классового общества неизбежен.

2. Первый президент России и правительство в угоду своим американским советникам сознательно отказывались не только от социалистической, но и от любой другой идеологии, потому что американские партнёры убедили всех, что любая идеология - это сущность тоталитарного государства. Но так ли это? Идеология должна быть как отражение взглядов большинства. Она нужна прежде всего народу, который именно с Россией связывает своё настоящее и будущее своих детей и внуков. Государство без объединяющей идеологии не может существовать. Отсутствие внятной, положительной идеологии лишь усилило социальное неравенство в России, разобщила народ, поставив его на грань раскола.

России необходима своя идеология, которая не только сплотит народ, но и сделает его процветающей нацией. Поэтом шагом вперед должно стать появление идеологии, признающей равенство прав и возможностей граждан, вне зависимости от их политического и экономического статуса. И это равенство должно охватить всю политическую жизнь об- 
щества, всех субъектов публичных отношений, коснуться каждого гражданина. Только в этом случае народный суверенитет наполнится новым содержанием, освободится от чрезмерной обузы полновластного политического посредничества.

Таким образом, национальная идея российского народа заключается в торжестве народного суверенитета, власти свободных граждан с равными правами и возможностями в области управления делами государства. Роль прямой демократии возрастает, востребованы модели участия масс в решении публичных вопросов. Тут без новой конституции не обойтись. Она и станет программой нового универсума нашего общества, избавит его от накопившихся «социальных болезней».

Надо не упустить исторический шанс по дальнейшему развитию российской государственности.

\section{Список источников}

1. Гурвич Г.С. 1958. Народ, народный суверенитет и народное представительство в советской системе. Советское государство и право, 12: 38-47.

2. Данилевский Н.Я. 1991. Россия и Европа. М., Книга, 576 с.

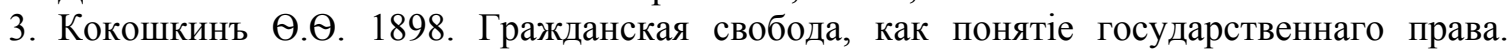
Сборник ПравовЊдънія и общественныхъ знаній. Томъ восьмой. Москва: Товарищество типографіи А.И. Мамонтова: 228-246.

\section{Список литературы}

1. Борисов Г.А., Комаров И.М., Кучин О.С., Мархгейм М.В., Нифанов А.Н., Новикова А.Е., Носков В.А., Тонков Е.Е. 2016. Государство созидающее: юридическая модель и современные риски. Под ред. О.Н. Полухина. М., Юрлитинформ, 416 с.

2. Заславская Т.И. 1995. Структура современного российского общества. Мониторинг общественного мнения: экономические и социальные перемены, 6: 7-13.

3. Ермаков М. 2013. Новая формация: бесклассовое общество или информационный капитализм. Власть. 9: 106-110.

4. Жвитиашвили А.Ш. 2017. Классовые схемы современного общества в западной социологии. Социологическая наука и социальная практика, том 5, № 1 (17): 7-23.

5. Кокотов А.Н. 2018. Конституция России и «болезнь самоотречения». Вестник Саратовской государственной юридической академии, 1 (120): 11-15.

6. Макогон Б.В. 2017. Методологически опорная трактовка юридического процесса. Наука и образование: хозяйство и экономика; предпринимательство; право и управление. 1 (80): $32-35$.

7. Мамут Л.С. 1989. Этатизм анархизм как типы политического сознания. М.: Наука: 256 с.

8. Ревина И.В. 2000. Формирование среднего класса как результат экономических реформ. Омский научный вестник, декабрь: 45-50.

9. Романчук И.С. 2010. Правовое государство в политической системе современного общества: миф или реальность? Правовое государство: теория и практика, 1(19): 66-69.

10. Сорокин В.В. 2010. Общее учение о государстве и праве переходного периода. М., Юрлитинформ: 424 с.

11. Тонков Е.Е. 2011. Юридические формы государственной деятельности: трансформация в условиях экономического кризиса. Российская юстиция, 6: 2-6.

12. Тощенко Ж.Т. 2018. Прекариат. От протокласса к новому классу. М., Наука»: 350 с.

13. Kuksin I.N., Markhgeym M.V., Novikova A.E., Tonkov E.E. 2016. Justice as principle: aspects of genesis in social and regulatory systems. The Social Sciences (Pakistan), 11 (10): 2367-2370.

14. Makogon B.V., Savel'eva I.V., Lyahkova A.I., Parshina A.A., Emel'anov A.S. 2017. Interpretation of legal responsibility as a universal instrument of procedural legal restrictions. The Turkish Online Journal of Design Art and Communication, 7 (№ S-APRLSPCL): 328-332.

\section{References}

1. Borisov G.A., Komarov I.M., Kuchin O.S., Markhgeym M.V., Nifanov A.N., Novikova A.E., Noskov V.A., Tonkov E.E. 2016. Gosudarstvo sozidajushhee: juridicheskaja mod-el' i sovremennye riski. 
[The creative state: the legal model and modern risks]. Edited by O.N. Polukhin, M., Publ. Yurlitinform, $416 \mathrm{p}$.

2. Zaslavskaya T.I. 1995. The structure of contemporary russian society: methodology of research. Monitoring obshchestvennogo mneniya: ekonomicheskie i sotsial'nye peremeny, 7-13 (in Russian).

3. Ermakov M. 2013. Novaya formaciya: besklassovoe obshchestvo ili informacionnyj kapitalizm [New formation: classless society or information capitalism]. Vlast' [Power]. 9: 106-110.

4. ZHvitiashvili A.SH. 2017. Class schemes of modern society in western sociology. Sociologicheskaya nauka i social'naya praktika, Vol. 5, No. 1(17): 7-23. (in Russian)

5. Kokotov A.N. 2018. The constitution of Russia and "disease of self-denial". Vestnik Saratovskoj gosudarstvennoj yuridicheskoj akademii, 1 (120): 11-15 (in Russian).

6. Makogon B.V. 2017. Metodologicheski opornaja traktovka juridicheskogo processa [Methodologically supporting interpretation of the legal process]. Nauka i obrazovanie: hozjajstvo i jekonomika; predprinimatel'stvo; pravo i upravlenie, 1 (80): 32-35.

7. Mamut L.S. 1989. Etatizm anarhizm kak tipy politicheskogo soznaniya [Statism anarchism as types of political consciousness]. M., Publ. Nauka, $256 \mathrm{p}$.

8. Revina I.V. 2000. Formirovanie srednego klassa kak rezul'tat ekonomicheskih reform [Formation of the middle class as a result of economic reforms]. Omskij nauchnyj vestnik, December: $45-50$.

9. Romanchuk I.S. 2010. Rule-of-iaw state in the political system of contemporary society: a myth or reality? Pravovoe gosudarstvo: teoriya i praktika, 1(19): 66-69 (in Russian).

10. Sorokin V.V. 2010. Obshchee uchenie o gosudarstve i prave perekhodnogo perioda [General doctrine of the state and law of the transition period]. M., Publ. YUrlitinform, $424 \mathrm{p}$.

11. Tonkov E.E. 2011. YUridicheskie formy gosudarstvennoj deyatel'nosti: transformaciya $v$ usloviyah ekonomicheskogo krizisa [Legal forms of state activity: transformation in the context of the economic crisis]. Rossijskaya yusticiya, 6: 2-6.

12. Toshchenko ZH.T. 2018. Prekariat. Ot protoklassa k novomu klassu [Precariat. From the proto-class to the new class]. M., Publ. Nauka, 350 p.

13. Kuksin I.N., Markhgeym M.V., Novikova A.E., Tonkov E.E. 2016. Justice as prin-ciple: aspects of genesis in social and regulatory systems. The Social Sciences (Pakistan), 11 (10): 2367-2370.

14. Makogon B.V., Savel'eva I.V., Lyahkova A.I., Parshina A.A., Emel'anov A.S. 2017. Interpretation of legal responsibility as a universal instrument of procedural legal restrictions. The Turkish Online Journal of Design Art and Communication, 7 (№ S-APRLSPCL): 328-332.

\section{ИНФОРМАЦИЯ ОБ АВТОРАХ}

Куксин Иван Николаевич, доктор юридических наук профессор кафедры истории и теории государства и права ИПиУ МГПУ, Москва; профессор кафедры конституционного и международного права юридического института НИУ «БелГУ», Белгород, Россия

Селихов Николай Васильевич, кандидат юридических наук, независимый исследователь

\section{INFORMATION ABOUT THE AUTHORS}

Ivan N. Kuksin, doctor of law, Professor of the Department of history and theory of state and law, Ipiu MSPU, Moscow, Russia and Professor of the Department of constitutional and international law, BelSU law Institute, Belgorod, Russia

Nikolay V. Selikhov, $\mathrm{PhD}$ in law, independent researcher 